American Journal of Nanotechnology 1 (1): 23-31, 2010

ISSN 1949-0216

(C) 2010 Science Publications

\title{
Research in the Improvement of Wettability of Micro-Structure in Patterned Electrodeposition
}

\author{
Li Guangyang, Wang Hong, Yuan Yang, Yao Jinyuan, Yang Zhuoqing and Ding Guifu \\ National Key Laboratory of Nano/Micro Fabrication Technology, \\ Key Laboratory for Thin Film and Micro-Fabrication of Minister of Education, \\ Research Institute of Nano/Micro Science and Technology, \\ Shanghai Jiao Tong University, Shanghai 200240, China
}

\begin{abstract}
Problem statement: The high aspect-ratio electrodeposition was widely used in the manufacture of non-silicon MEMS devices. The wetting of high aspect-ratio micro-structure in electrolyte was important to the uniformity of micro-structure. Approach: In this study, to enhance the wettability of micro-structures in electrolyte, the effect of Sodium Dodecyl Sulfate (SDS) and $\mathrm{O}_{2}$ plasma surface modification were discussed. Contact Angles (CA) between nickel sulfamate and the micro-structure were investigated to test the effect of two ways mentioned above. We employ the plasma photoresist-removal machine to modify micro-structure made of photoresist and the effects of different modification time were also discussed. The mechanism of $\mathrm{O}_{2}$ plasma treatment was investigated. According to Cassie's law, a new method was proposed to follow the wetting progress of micro-structure. Results: The contact angles between the electrolytes with SDS and smooth photoresist surfaces exposed to $\mathrm{O}_{2}$ plasma surface modification decreased from $90-5.2^{\circ}$ continuously. The maximum SDS concentration was $1 \mathrm{~g} \mathrm{~L}^{-1}$ and the longest modification time was 60s. After 30 min's quiescence, the micro-structure was completely filled by electrolyte, with the size of $50 \times 50 \times 50 \mu \mathrm{m}$ (width $\times$ width $\times$ height $\times$ ). Conclusion/Recommendation: It was possible to promote the wettability by introduction of SDS as wetter and the employment of $\mathrm{O}_{2}$ plasma surface modification. The effect of $\mathrm{O}_{2}$ plasma surface modification could be attributed to the introduction of free and associated hydroxyl.
\end{abstract}

Key words: Micro-structure, associated hydroxyl, $\mathrm{O}_{2}$ plasma, Contact Angles (CA), Sodium Dodecyl Sulfate (SDS), micro-cavity, cold plasma, hot plasma, plasma ionization, wetting process

\section{INTRODUCTION}

Unlike conventional silicon-based MEMS process, the non-silicon methods to fabricate MEMS devices have been widely used (Duan et al., 2006; Wisitsoraat et al., 2006; Xiao-Chuan, et al., 2009; Haogang et al., 2009; Yuan et al., 2003; Yuan et al., 2006; Gaoyin et al., 2009; Yibo et al., 2010a;2010b; Zhuoqing et al., 2009; Haogang et al., 2008a;2008b; Xiaofeng et al., 2008). The main material applied in non-silicon process was metal. Metals could be used to create MEMS elements. Although metals do not have some of the advantages displayed by silicon in terms of mechanical properties, when used within their limitations, metals can exhibit very high degrees of reliability. Metals can be deposited by electroplating, evaporation and sputtering processes. Most of non-silicon MEMS devices could be fabricated following the process depicted in Fig. 1. The copper and chrome were sputtered on glass substrate as sacrifice layer and joint layer (Fig. 1a). The photo-resist which was sputtered on copper could be divided into two classes: positive and negative photo-reisit (Fig. 1b). When it was exposed to radiation sources, the positive photo-resist would be easily removed by wet etching solution. The pattern was transferred into photo-resist through lithography by selective exposure, then, the exposed photo-resist was removed by wet etching solution (Fig. 1c). Followed by electrodeposition, the metal micro structure was formed (Fig. 1e). It is necessary to repeat step (b-e), when the devices with complicated structures needed to be prepared. Finally, after the remove of copper and chrome, the devices were released (Fig. 1f).

Corresponding Author: Wang Hong, National Key Laboratory of Nano/Micro Fabrication Technology, Key Laboratory for Thin Film and Micro-Fabrication of Minister of Education, Research Institute of Nano/Micro Science and Technology, Shanghai Jiao Tong University, Shanghai 200240, China Fax: +86-21-34206686 


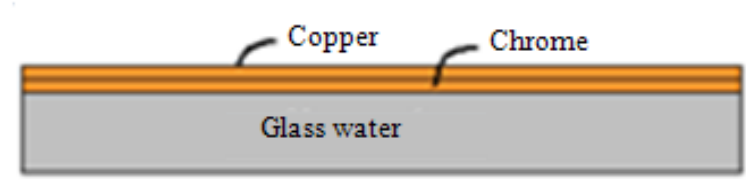

(a)

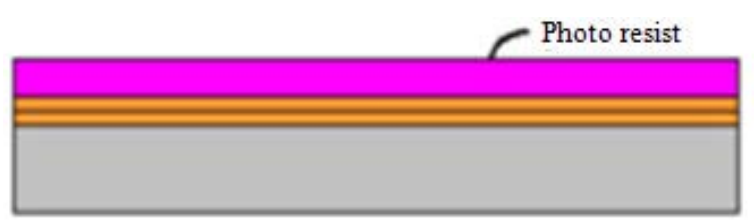

(b)

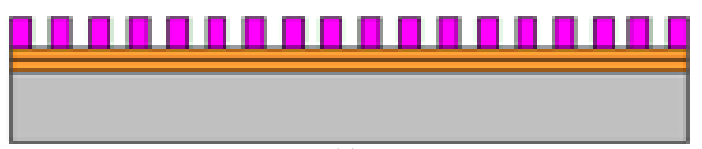

(c)

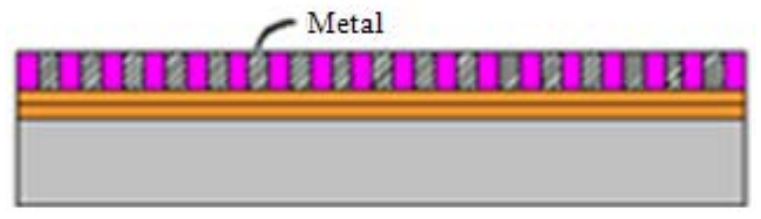

(d)

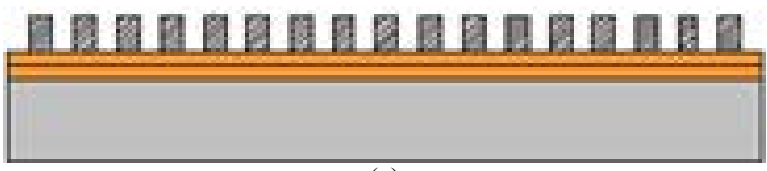

(e)

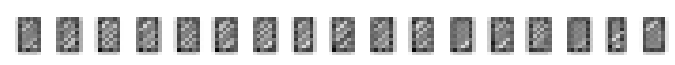

(f)

Fig. 1: The flow chat of non-silicon manufacture

The step d described above was crucial to the quality of MEMS devices so formed. The uniformity of electrodeposition of metal in micro-cavity has attracted more attentions (Kondo and Fukui, 1998; Hayashi et al., 2001; Selvakumari et al., 2009). In aspect-ratio patterned electrodeposition, as the aspect-ratio increased continuously, because of surface tension and the air trapped in the micro-cavity, mass transferring of electrolyte in the micro-cavity became more and more difficult (Yang and Kang, 2000; Iskandarani and Shilbayeh, 2005). To enhance the mass transferring in micro-cavity is very useful to the improvement of the uniformity of electrodeposition. As to the mass transferring, firstly, the electrolyte in plating bath need to infiltrate into the micro-cavity. Secondly, the electrolyte should refresh ceaselessly to maintain the reaction on the cathode surface. So it is unquestionable that the promotion of wettability of electrolyte would improve the quality of electrodeposition. The introduction of wetter is proper way to improve the surface contact angle (Wei et al., 2000; Dezianian et al., 2010; Yusilawati et al., 2010). But, the research on the effect of the concentration of wetter in the electrolytes was not sufficient. In this study we would like to discuss this problem quantificationally.

As it is well known that the water droplet will have the shape of spherical cap on the hydrophilic or hydrophobic surface (Zhu et al., 2006; Antonelli et al., 2010). Only on the super-hydrophilic surface, the water droplet would completely spread out. The microstructure must be easily wetted if the surface of the structure was superhydrophilic. It has been proposed that the surface properties could be tuned by plasma treatment and Surface modification with plasma was widely employed to improve the material's surface properties (Lejeune et al., 2006; Chung and Hong, 2007; Masakuni et al., 2010; Sheng-Hsiang et al., 2009; Fresnais, et al., 2009; Darnon et al., 2008; Posseme et al., 2007; Youngsoo et al., 2007; Neal et al., 2010; Schulte et al., 2009; Ji Geun et al., 2009; Qindeel et al., 2007; AL-Medhtiy et al., 2009). Plasma treatment is the most popular surface modification process of polymer. Plasma modification is clear, quickly reacted, produces low pollution, coating. During the process of plasma excitation, there are atoms, ions, radicals and UV-light produced in the plasma treatment chamber (Gancarz et al., 2003; Jimmy and Usoh, 2009). Plasma can improve the properties like wettability, permeability, conductivity, printability, adhesion, or biocompatibility of the polymer surface (Yang and Gupta, 2004; Mohammad et al., 2010). Based on the relative temperatures of the electrons, ions and neutrals, plasmas are classified as "thermal" or "non-thermal". Thermal plasmas have electrons and the heavy particles at the same temperature, i.e., they are in thermal equilibrium with each other. Non-thermal plasmas on the other hand have the ions and neutrals at a much lower temperature, (normally room temperature), whereas electrons are much "hotter". Temperature controls the degree of plasma ionization. In particular, plasma ionization is determined by the "electron temperature" relative to the ionization energy, in a relationship called the Saha equation ( $\mathrm{Nad}, 1921$; Irving et al., 1923). A plasma is sometimes referred to as being "hot" if it is nearly fully ionized, or "cold" if only a small fraction of the gas molecules are ionized, but other definitions of the terms "hot plasma" and "cold plasma" are common. Even in"cold" plasma, the electron temperature is still typically several thousand degrees Celsius. Plasmas utilized in "plasma technology" are usually cold in this sense. Small cold plasma zone treatment is an important modification technique in modern industry (Sheng and Xiao-Ming, 
Am. J. Nanotech., 1 (1): 23-31, 2010

2002; Belov, 2004; Takeshi and Hideomi, 2004). It is possible to promote the hydrophilicity of microstructure consisted of positive photo-resist by plasma treatment.

The Contact Angles (CA) is widely used to characterize the hydrophilicity and hydrophobicity. It have been defined that the CA of hydrophobic surface was lager than $90^{\circ}$ and smaller than $90^{\circ}$ on hydrophilic surface. The contact angles between electrolytes and micro-structures were the symbol of the wettability of electrolytes and the hydrophilicity of micro-structure. It is apparent that surface of micro-structure is rough. There are two different models to describe the wetting process of rough surface, the Wenzel's (Patankar, 2003) model and Cassie's (He et al., 2003) model (Fig. 2). Wenzel assumed that a liquid completely fills the depressions in the region where it contacts with the substrate, as shown in Fig. 2a. Hereafter it was referred to as the "wetted surface." The apparent CA with Wenzel model $\theta_{\mathrm{A}}{ }^{\mathrm{W}}$ is given by:

$\cos \theta_{\mathrm{A}}{ }^{\mathrm{W}}=\mathrm{r} \cos \theta_{\mathrm{I}}$

Where:

$r=$ The ratio of the actual area of the rough surface to the projected area

$\theta_{1}=$ The intrinsic contact angle between water droplet and smooth surface

Cassie's theory assumed that a composite surface is formed when a droplet contacts with a rough surface and the liquid is completely lifted up by the roughness features, as shown in Fig. 2b.The apparent CA with Cassie model is given by:

$\cos \theta_{\mathrm{A}}{ }^{\mathrm{C}}=\mathrm{f}_{\mathrm{S}}\left(1+\cos \theta_{\mathrm{I}}\right)-1$

where, $f_{s}$ is the ratio of the area contacting with the droplet of the rough surface to the projected area.

Apparently, to keep the consistent of the electrodepostion, the electrolyte should fill the microstructure completely. In this study, with the combination of the introduction of wetter and $\mathrm{O}_{2}$ Plasma surface treatment, the wetting process of micro-structure was investigated. Because of the invisibility of the wetting cause, an equation was deduced based on Cassie's theory. We discussed the effects of the concentration of SDS in electrolyte and the $\mathrm{O}_{2}$ Plasma surface treatment duration quantatively. And the mechanism of $\mathrm{O}_{2}$ Plasma surface treatment was also discussed.

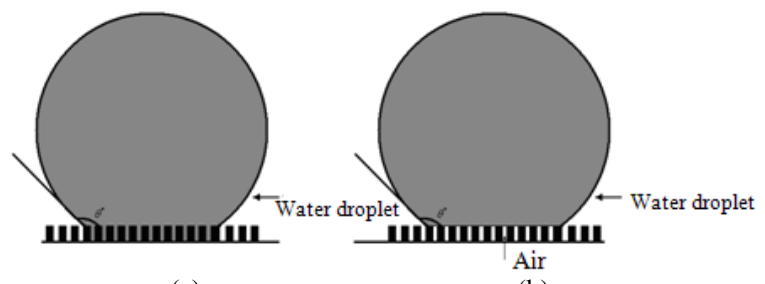

(a)

(b)

Fig. 2: Wenzel model and Cassie model of water droplet on rough surface, (a) Wenzel model; (b) Cassie's mode

\section{MATERIALS AND METHODS}

A simple electrolyte composition containing $420 \mathrm{~g}$ $\mathrm{L}^{-1}$ of nickel sulfamate [Ni (NH2SO3)2.4H2O] and 40 $\mathrm{g} \mathrm{L}^{-1}$ of boric acid was adopted to produce nickel electroforms and to test surface contact angle between photoresist and electrolyte droplet. The test was finished at $25^{\circ} \mathrm{C} . \mathrm{O} 2$ Plasma Surface Treatment with different treatment time was investigated. The polarization curves of electrolytes with different wetter concentration were measured by electrochemical work station. The positive photoresist(AZ-K50) with the thickness of $50 \mu \mathrm{m}$ was sputtered on copper seed layer that was scattered on glass. Then the photoresist was exposed to $\mathrm{O}_{2}$ Plasma, treatment time differed from $5 \mathrm{~s}$ to 60 s. Positive photoresist micro-structure with copper as seed layer was prepared by the wet etching via a mask pattern. Electroforming process was subsequently employed for fabricating three-dimensional microstructures. Electroforming was conducted at the $25^{\circ} \mathrm{C}$. The micro-structure used in this experiment was made following the process depicted in Fig. 1. The photoresist was positive, which could be dissolved by wet etching solution ( $3 \mathrm{wt} \% \mathrm{NaOH}$ solution) when exposed to ultraviolet light.

In this research, contact angles between photoresist and electrolytes were used to analyze the wetting process. The introduction of wetter was a primary way to improve the wetting capacity of electrolyte on the photoresist. In this study, the effect of Sodium Dodecyl Sulfate (SDS) which is widely used as wetter was tested.

In this experiment, the width of the micro-cavity of micro-structure was only 50um, it was impossible to observe the wetting process directly. So, we proposed an assumption and an equation based on the Eq. 2 referred above. It was clear that when the $r$ equals 1 and the $\mathrm{f}_{\mathrm{S}}$ equals 1 , we may export: $\cos \theta_{\mathrm{I}}=\cos \theta_{\mathrm{A}}{ }^{\mathrm{W}}=\cos \theta_{\mathrm{A}}{ }^{\mathrm{C}}$. So, if the surface packed with micro-cavities was completely wetted, the apparent angle of the surface should be equal to the intrinsic angle of the smooth surface. That was: 
$\frac{1+\cos \theta_{A}{ }^{\mathrm{C}}}{1+\cos \theta_{\mathrm{I}}}=\mathrm{f}_{\mathrm{S}}$

Based on the values of $\theta_{A}{ }^{C}$, the $f_{s}$ could be calculated correspondingly. If the $\mathrm{f}_{\mathrm{s}}=1$, the $\theta_{\mathrm{A}}{ }^{\mathrm{C}}=\theta$ the micro-cavities were totally filled by electrolyte. Actually, the electroplating result were influenced by many factors, such as the distribution of current density 、 mechanical agitation, concentration of electrolyte. As the advancement of the electrodepostion, it was dreadful to figure out the effects of these factors. So, to define the consequence of the introduction of wetter and the application of $\mathrm{O}_{2}$ plasma treatment, we observed the topography of the nickel layer after 90s' plating.

\section{RESULTS}

Contact angle between electrolyte with different SDS concentration and resist under different $\mathrm{O}_{2}$ plasma treatment duration was investigated (Fig. 3). The result of the Fig. 3 showed contact angles between electrolyte and photoresist without surface treatment decreased as the concentration of SDS increased. The contact angle of wetter-free electrolyte was $91^{\circ}$. While the concentration of SDS increased to $0.5 \mathrm{~g} \mathrm{~L}^{-1}$, the contact angle decreased to $29.4^{\circ}$. It was notable that contact angle changed dramatically during the addition of SDS to $0.1 \mathrm{~g} \mathrm{~L}^{-1}$, then contact angle remained steady even the concentration of SDS increased to $1 \mathrm{~g} \mathrm{~L}^{-1}$. In the research, the nickel sulfamate solution with $1 \mathrm{~g} \mathrm{~L}^{-1} \mathrm{SDS}$ became opaque after $24 \mathrm{~h}$ quiescence in room temperature.

It showed that the effect of plasma treatment wasn't directly proportional to treatment time. Take the top profile for example, after $5 \mathrm{~s}^{\prime} \mathrm{O}_{2}$ plasma treatment, contact angle decreased from $90-54.2^{\circ}$ swiftly. Then, as the advance of plasma treatment time, contact angle changed little. Four profiles ordered from high to low, according to the concentration of SDS.

The contact angle between wetter-free electrolyte and photoresist surface without plasma treatment was $90^{\circ}$, whereas the contact angle between electrolyte with $1 \mathrm{~g} \mathrm{~L}^{-1} \mathrm{SDS}$ and photoresist that was treated by $\mathrm{O}_{2}$ plasma for $5 \mathrm{~s}$ was $5.2^{\circ}$. With electrochemical test, it was obvious that the deposition potential of nickel in electrolytes with different SDS concentration was not changed. However, as we mentioned before, the nickel sulfamate solution with $1 \mathrm{~g} \mathrm{~L}^{-1}$ SDS became opaque after $24 \mathrm{~h}$ 's quiescence in room temperature, because of the precipitation of SDS. After heating, the solution returned to the state of transparency. So in the following experiment, we employed nickel sulfamate solution with $0.5 \mathrm{~g} \mathrm{~L}^{-1} \mathrm{SDS}$. According to the Fig. 3, the proper duration of $\mathrm{O}_{2}$ plasma treatment was $5 \mathrm{~s}$.

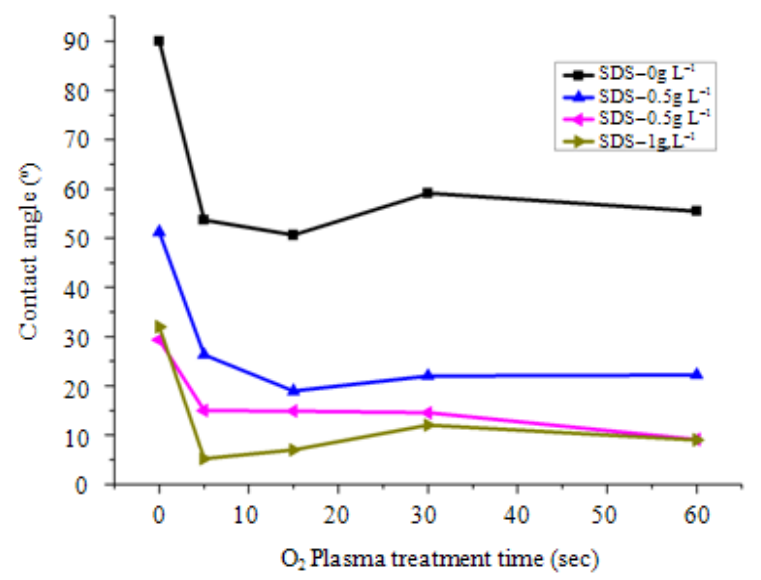

Fig. 3: Contact angles between electrolytes with different SDS concentration and photoresist surfaces under variable plasma treatment time

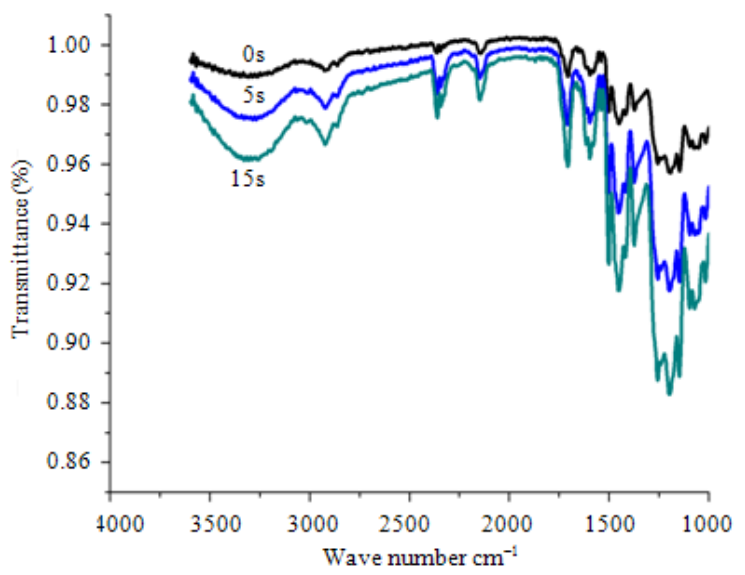

Fig. 4: FTIR of photoresist surfaces under different $\mathrm{O}_{2}$ plasma treatment duration

To investigate the origin of hydrophilicity of the photoresist film, we analyzed the surface of the film by reflection infrared spectroscopy. Fig. 4 shows the reflection IR spectra of the hydrophilic film surface for each plasma treatment. Compared to the top curve which the treatment time was $0 \mathrm{~s}$, the peak for free hydroxyl at about 1400 and $1150 \mathrm{~cm}^{-1}$ and the peak for associated hydroxyl Increased in middle curves. 
Am. J. Nanotech., 1 (1): 23-31, 2010

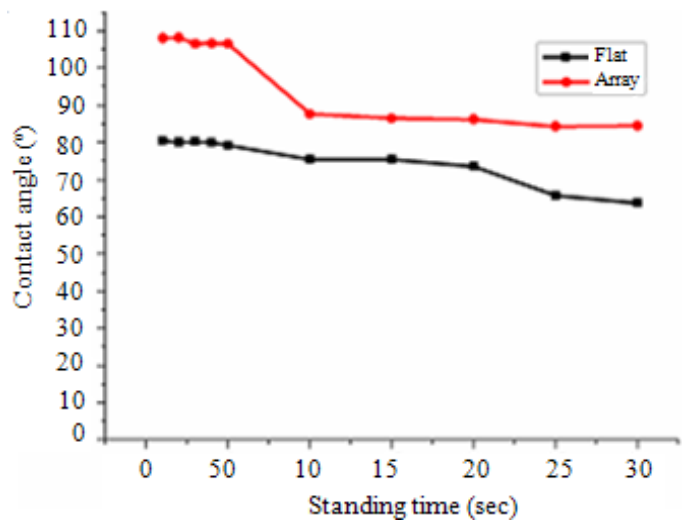

(a)

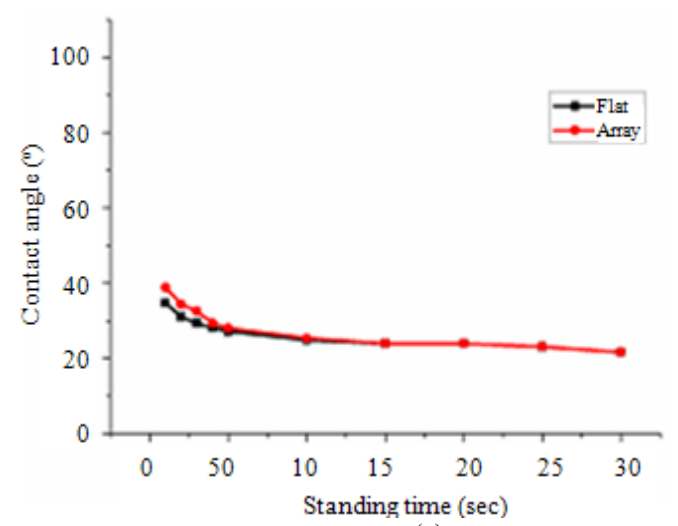

(c)

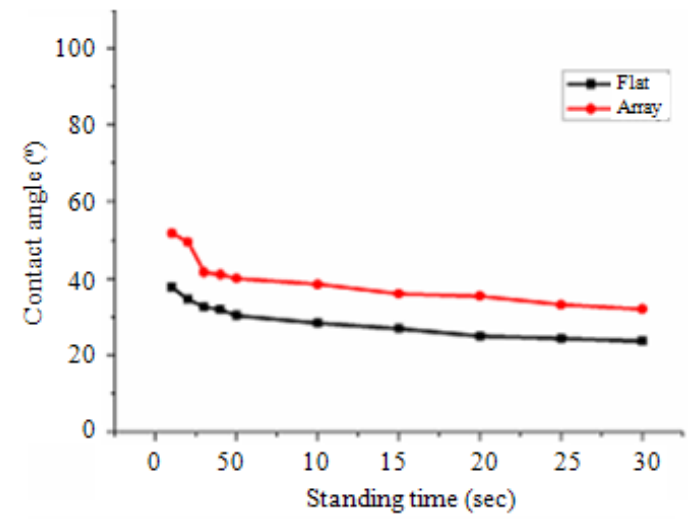

(b)

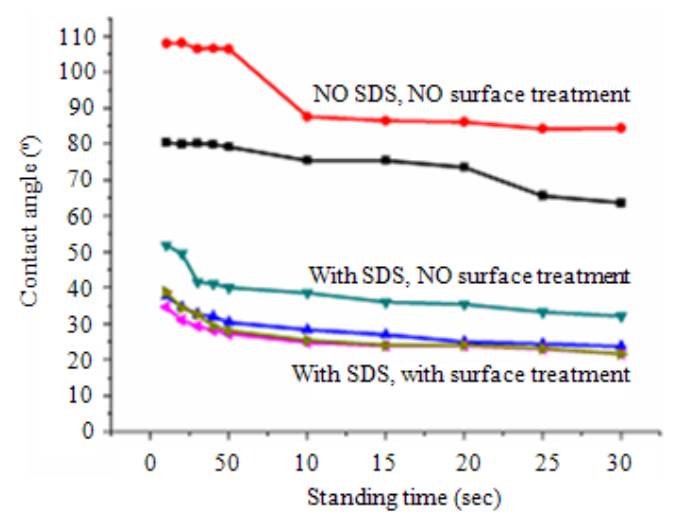

(d)

Fig. 5: Comparison of dynamic contact angles of micro structure and flat photoresist surfaces under three conditions during the same standing time. (a) electrolyte without SDS, no $\mathrm{O}_{2}$ plasma surface treatment; (b)electrolyte with $0.5 \mathrm{~g} / \mathrm{L} \mathrm{SDS}$, no $\mathrm{O}_{2}$ plasma surface treatment;(c) electrolyte with $0.5 \mathrm{~g} / \mathrm{L} \mathrm{SDS}, \mathrm{O}_{2}$ plasma surface treatment for $5 \mathrm{~s} ;(\mathrm{d})$ collective diagram of $(\mathrm{a})(\mathrm{b})(\mathrm{c})$

As we know, the hydroxyl is hydrophilic, with the presence of hydroxyl could enhance the wettability of the photoresist film. However, the increase of hydroxyl failed to enhance the hydrophilicity of film continually, as the Fig. 3 depicted. We had also found that with the $\mathrm{O}_{2}$ plasma surface treatment for $5 \mathrm{~s}$ by resist remover, the wettability of the side wall of the micro structure prepared before has greatly changed. So the effect of the $\mathrm{O}_{2}$ plasma treatment of resist remover was isotropic.

In the following experiment, the micro structure was prepared by UV-LIGA process. The aspect ratio of the micro structure array prepared in our research was 1 , with a depth of $50 \mu \mathrm{m}$ and a width of $50 \mu \mathrm{m}$. The infiltration of electrolyte in micro-cavity was important to the result of electrodeposition. Enhance the infiltration of electrolyte would promote the exchange between fresh external electrolyte outside the cavity and the depleted electrolyte in the cavity and increased the plating rate, resulted in uniform nickel surface.
According to Cassie's law for surface wettability, the apparent contact angle $\theta^{*}$ of such film with micro structure array is described by:

$\cos \theta_{\mathrm{A}}{ }^{\mathrm{C}}=\mathrm{f}_{\mathrm{S}}\left(1+\cos \theta_{\mathrm{I}}\right)-1$

So:

$\frac{1+\cos \theta_{\mathrm{I}}}{1+\cos \theta_{\mathrm{A}}{ }^{\mathrm{C}}}=\mathrm{f}_{\mathrm{S}}$

Where:

$\mathrm{f}=$ Area fraction of micro-structure

1-f $=$ Area fraction of air trapped in the micro structure

$\theta_{\mathrm{I}}=$ Intrinsic contact angle of the smooth photoresist film 


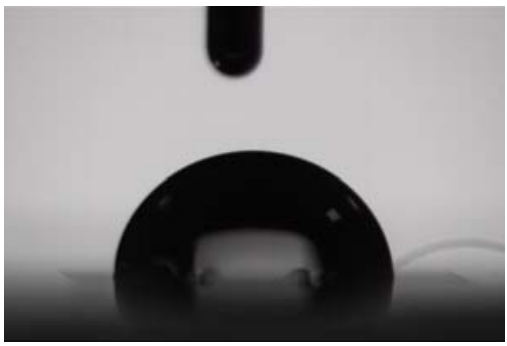

(a)

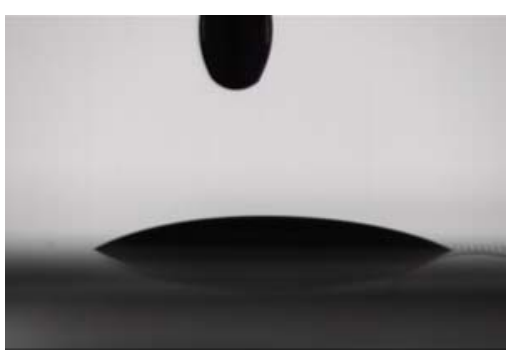

(b)

Fig. 6: Contact angles between micro-structure and electrolyte droplet

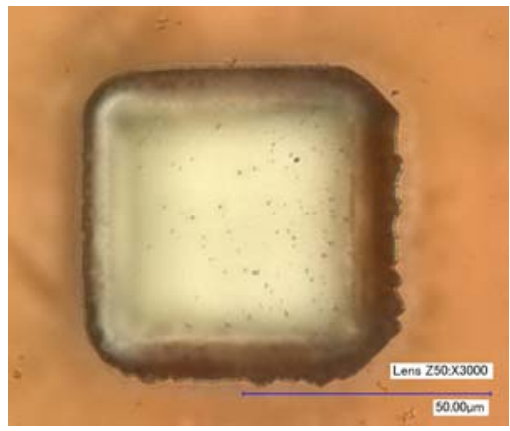

Fig. 7: Image of nickel layer of micro-structure after 90's electrodeposition

We could conclude from the formula above that if the micro cavity was completely filled with electrolyte, the $\mathrm{f}$ equals 1 and the apparent angle $\theta_{\mathrm{A}}{ }^{\mathrm{C}}$ must be equal to intrinsic contact angle $\theta_{\text {I }}$ of smooth photoresist.

When the electrolyte droplet dropped on the surface packed with micro-cavities, the air trapped in the hole stopped the infiltration of electrolyte into the cavity in the case of without the introduction of wetter and plasma surface treatment. The infiltration of electrolyte into micro cavity was dynamic process, so with the help of CCD camera, we documented the contact angles at different standing time.

Dynamic contact angle between electrolyte without SDS and surface without $\mathrm{O}_{2}$ plasma surface treatment was depicted in Fig. 5 a. After 30minutes' quiescence, calculated $\mathrm{f}$ was 0.76 , the cavity had not been filled entirely. It was notable that the calculated $\mathrm{f}$ in Fig. 5b was 0.96 , the presence of wetter promoted the wettability of micro structure obviously. As it was depicted in Fig. $5 \mathrm{c}$, the apparent angle was equal to intrinsic angle at 15 minute, calculated $\mathrm{f}$ was 1 and the micro cavity was filled by electrolyte completely.

Figure 6 displayed the Contact Angles (CA) of micro-structure, it was clear that the application of $\mathrm{O}_{2}$ plasma treatment and the introduction of wetter decreased the contact angle between micro-structure and electrolyte. So, as we discussed above, it was easier for electrolyte to infiltrate into the micro-cavity of micro-structure.

Left: CA:84.38 ${ }^{\circ}$ : Micro-structure without plasma treatment, electrolyte without SDS.

Right: CA:21.56 ${ }^{\circ}$ : Micro-structure under $\mathrm{O}_{2}$ plasma treatment for $5 \mathrm{~s}$, electrolyte with $0.5 \mathrm{~g} \mathrm{~L}^{-1} \mathrm{SDS}$.

The following image depicted the result of 90s'electrodeposition. The micro-structure (aspect-ratio $=1$, depth $=50 \mu \mathrm{m}$, width $=50 \mu \mathrm{m}$ ) was immersed in electrolyte as cathode. The topography of nickel layer deposited on seed layer was observed with microscope (Fig. 7).

With the introduction of wetter and the application of $\mathrm{O}_{2}$ plasma treatment, the wettability of microstructure was improved. The hydrogen bubble which evolved in electroplating cause failed in adhering to the nickel layer, the electrolyte on the surface of nickel layer continually renewed by the agitation of hydrogen bubble dispersed into electrolyte. Fig. 7 was the topography of nickel layer in micro-structure which exposed to $\mathrm{O}_{2}$ plasma surface treatment for $5 \mathrm{~s}$ and deposited in electrolyte with SDS. It was obvious that after 90s' electrodeposition, there's no obvious pore and defect was observed, so the function of the presence of wetter in electrolyte and the application of $\mathrm{O}_{2}$ plasma surface treatment were proved.

\section{DISCUSSION}

The aims of this article were to define the effects of the enhancement of the wettability of the nickel electrolyte by introduction of wetter and the result of the $\mathrm{O}_{2}$ plasma surface treatment to the improvement of the hydrophilicity of micro-structure consisted of micro-cavities that fabricated by positive photoresist.

Different from available research, we found that the effect of the introduction of SDS as wetter failed to continue as the increased of the concentration of SDS. 
We also discovered that the polarization curves haven't been affected by wetter, the deposition potential remained unchanged. But it was still inadequate to define the role that the SDS played in the electroplating through this experiment with one exception that the wettability of electrolyte was enhanced obviously. It had found that the hydrophilicity of positive photoresist was promoted by $\mathrm{O}_{2}$ plasma surface treatment. The result of FTIR demonstrated that the slight augment of the free and associated hydroxyl. As to the aspect-ratio structure used in this experiment, the effect of the plasma treatment was isotropic. However, further research still needed to figure out whether such isotropic effect could be tuned by the change of aspectratio and the width or diameter of the micro-cavity.

\section{CONCLUSION}

The roles of the introduction of wetter and the application of plasma surface treatment on the wetting property of micro structure prepared by LIGA technology were discussed. It proved that with the introduction of SDS as wetter, the infiltration of nickel sulfamate electrolyte in micro-structure was greatly enhanced. As to $\mathrm{O}_{2}$ plasma surface treatment, with the presence of free hydroxyl and associated hydroxyl observed through FTIR, the wettability of the photoresist surface improved obviously. It was notable that the $\mathrm{O}_{2}$ plasma surface treatment by resist remover was isotropic, so the application of the $\mathrm{O}_{2}$ plasma surface treatment in improvement of wetting property of micro-structure prepared by UV-LIGA technology was possible. In the experiments, we've found that the micro structure (width $=50 \mu \mathrm{m}$, depth $=50 \mu \mathrm{m}$ ) which exposed to the $\mathrm{O}_{2}$ plasma surface treatment for $5 \mathrm{~s}$ was completely filled by nickel sulfamate electrolyte with $0.5 \mathrm{~g} \mathrm{~L}^{-1} \mathrm{SDS}$ as wetter.

\section{ACKNOWLEDGEMENT}

The researcher greatly acknowledges the financial support of The Nano Special Program of Science and Technology Commission of Shanghai Municipality under the grant no $1052 \mathrm{~nm} 02200$.

\section{REFERENCES}

AL-Medhtiy, M.H., A.B.Z. Zuki, M.M. Noordin and S. Agungpriyono, 2009. Secretary IgA concentrations and plasma cell count changes associated with the estrous cycle in ewes. Am. J. Anim. Vet. Sci., 4:2125. DOI: 10.3844 /ajavsp.2009.21.25
Antonelli, D., G. Fantoni, M. Porta and M. Santochi. A methodology for the selection of micro-assembly techniques. Am. J. Eng. Applied Sci., 3: 718-722. DOI: 10.3844/ajeassp.2010.718.722

Belov, S.V., 2004. Technology of high-frequency cold plasma ablation for small-invasion electro surgery. Meditsinskaya Tekhnika, 2: 25-30. PMID: 15148887

Chung, C.K. and Y.Z. Hong, 2007. Surface modification of SU8 photoresist for shrinkage improvement in a monolithic MEMS microstructure. J. Micromech. Microeng., 17: 207-212. DOI: 10.1088/0960-1317/17/2/004

Darnon, M., T. Chevolleau, T. David, N. Posseme and J. Ducote et al., 2008. Modifications of dielectric films induced by plasma ashing processes: Hybrid versus porous $\mathrm{SiOCH}$ materials. J. Vacuum Sci. Technol. Nanometer Structures, 26: 1964-1970. DOI: 10.1116/1.3006021

Dezianian, A., A.S. Sajap, W.H. Lau, D. Omar and H.A. Kadir et al., 2010. Morphological characteristics of p. xylostella granulovirus and effects on its larval host diamondback moth Plutella xylostella L. (Lepidoptera, Plutellidae). Am. J. Agric. Biol. Sci., 5: 43-49. DOI: 10.3844/ajabssp.2010.43.49

Duan, X., X. Fu, H. Xie and H. Yang, 2006. NonSilicon MEMS Calorimetric Gas Flow Sensor. Proceedings of the 1st IEEE International Conference Nano/Micro Engineered and Molecular Systems, Jan. 18-21, Zhuhai, pp: 658-661. DOI: 10.1109/NEMS.2006.334867

Fresnais, J., J.P. Chapel, L. Benyahia and F. PoncinEpaillard, 2009. Plasma-treated superhydrophobic polyethylene surfaces: Fabrication, wetting and dewetting properties. J. Adhesion Sci. Technol., 23: 447-467. DOI: 10.1163/156856108X370127

Gancarz, I., J. Bryjak, M.G. Pozniak and W. Tylus, 2003. Plasma modified polymers as a support for enzyme immobilization 1: Allyl alcohol plasma. Eur. Polymer J., 39: 1615-1622. DOI: 10.1016/S0014-3057(03)00055-7

Gaoyin, M., C. Wenyuan, X. Qijun, Z. Weiping and C. Feng et al., 2009. Single-neuron spinning control system for a non-silicon micromachined rotational gyro. Proceedings of the 4th IEEE International Conference on Nano/Micro Engineered and Molecular Systems, Jan. 5-8, Shenzhen, pp: 282285. DOI: 0.1109/NEMS.2009.5068578

Haogang, C., D. Guifu, Y. Zhuoqing, S. Zhijuan and Z. Jiansheng et al., 2008a. Design, simulation and fabrication of a novel contact-enhanced MEMS inertial switch with a movable contact point. J. Micromech. Microeng., 18: 1-11. DOI: 10.1088/0960-1317/18/11/115033 
Haogang, C., Y. Zhuoqing, D. Guifu and L. Rui, 2009. Development of a MEMS electrical inertia microswitch based on non-silicon substrate. J. Mech. Eng., 45: 156-161. http://en.cnki.com.cn/Article en/CJFDTOTALJXXB200903025.htm

Haogang, C., Y. Zhuoqing, D. Guifu and Z. Xiaolin, 2008 b. Fabrication of a MEMS inertia switch on quartz substrate and evaluation of its threshold acceleration. Microelectron. J., 39: 1112-1119. DOI: 10.1016/J.MEJO.2008.01.068

Hayashi, K., K. Fukui, Z. Tanaka and K. Kondo, 2001. Shape evolution of electrodeposited bumps into deep cavities. J. Electrochem. Soc., 148: 145-148. http://dx.doi.org/10.1149/1.1346602

He, B., N.A. Patankar and J. Lee, 2003. Multiple equilibrium droplet shapes and design criterion for rough hydrophobic surfaces. Langmuir, 19: 4999-5003. DOI: 10.1021/la0268348

Iskandarani, M.Z. and N.F. Shilbayeh, 2005. Design and Analysis of a Smart Multi Purpose Electronic Nose System. J. Comput. Sci., 1: 63-71. DOI: $10.3844 /$ jessp.2005.63.71

Ji Geun, J., S. Se Jin, L. Sung Kyoo, C. Ho Jung and R. Sang Ouk et al., 2009. Effect of plasma treatment of ITO electrode on the characteristics of green OLEDs with Alq3-C545T emissive layer. Molecular Cryst. Liquid Crystals, 498: 274-283. DOI: $10.1080 / 15421400802619602$

Jimmy, E.O. and I.F. Usoh, 2009. Plasma bilirubinaemia; A physiologic index for monitoring cellular effects of amalar, chloroquine, cotecxin and fansidar. Am. J. Pharmacol. Toxicol., 4: 85-88. DOI: 10.3844/ajptsp.2009.85.88

Kingdon, K.H. and L. Irving, 1923. The removal of thorium from the surface of a thoriated tungsten filament by positive ion bombardment. Phys. Rev., 22: 148-160. DOI: 10.1103/PhysRev.22.148

Kondo, K. and K. Fukui, 1998. Current evolution of electrodeposited copper bumps with photoresist angle. Electrochem. Soc., 145: 840-843. http://dx.doi.org/10.1149/1.1838354

Kondo, K. and K. Fukui, 1998. Shape evolution of electrodeposited bumps with deep cavity. Electrochem. Soc., 145: 3007-3010. http://dx.doi.org/10.1149/1.1838755

Lejeune, M., L.M. Lacroix and F. Bretagnol, 2006. Plasma-based process for surface wettability modification. Langmuir, 22: 3057-3061. DOI: 10.1021/la052515f

Masakuni, I., T. Ichiro, S. Tadashi, T., Shigeyuki and K. Yoshinori et al., 2010. The study of surface modification of indium-tin-oxide and resist surfaces with $\mathrm{CF}_{4} / \mathrm{O}_{2}$ plasma for manufacturing organic light-emitting diodes by inkjet printing. Jpn. J. Applied Phys., 47: 8935-8942. DOI: 10.1143/JJAP.47.8935

Mohammad, F.I., S. Awawdeh, A. Saleh and N.A. Bashir, 2010. Total level of serum homocysteine in males and females with coronary heart disease of different age groups. Am. J. Biochem. Biotechnol., 6: 116-119. DOI: 10.3844/ajbbsp.2010.116.119

Nad, S.M., 1921. On a Physical theory of stellar spectra. Proc. R. Soc. Lond., 99: 135-153. DOI: 10.1098/rspa.1921.0029

O’Neal, C.B. and J. Soman, 2010. The effects of plasma pretreatment and storage time on silicon fusion bonding. Proceedings of SPIE-The International Society for Optical Engineering, v 7592, Reliability, Packaging, Testing and Characterization of MEMS/MOEMS and Nanodevices IX, Jan. 25, San Francisco, California, USA. http://dx.doi.org/10.1117/12.839972

Patankar, N.A., 2003. On the modeling of hydrophobic contact angles on rough surfaces. Langmuir, 19: 1249-1253. DOI: 10.1021/la026612+

Posseme, N., T. Chevolleau, T. David, M. Darnon and O. Louveau et al., 2007. Mechanisms of porous dielectric film modification induced by reducing and oxidizing ash plasmas. J. Vac. Sci. Technol., 25: 1928-1940. DOI: 10.1116/1.2804615

Qindeel, R., N. Bidin and Y.M. Daud, 2007. IR laser plasma interaction with glass. Am. J. Applied Sci., 4: 1009-1015. DOI: 10.3844/ajassp.2007.1009.1015

Schulte, D.W., T. McMahon, D.D. Hall, M. Johnson and W. Stickle et al., 2009. Low temperature O2 plasma process for scanning capacitance sample preparation. Proceedings of the 35 th International Symposium for Testing and Failure Analysis, (ISTFA'09), pp: 140-143. http://asmcommunity.asminternational.org/portal/si te/edfas/AsmStore/ProductDetails/?vgnextoid=524 7acf82d847210VgnVCM100000621e010aRCRD\# details

Selvakumari, T.M., R.N. Emerson and S. Ganesan, 2009. Development of nanostructured stress free Pt-Rich FePt films for micro electro mechanical system applications. Am. J. Applied Sci., 6: 11751179. DOI: 10.3844/ajassp.2009.1175.1179

Sheng, Y. and H. Xiao-Ming, 2002. Solar-grade silicon material prepared by combining cold plasma with hydrometallurgy. J. Functional Mat., 33: 305-306. ISSN: 1001-9731 
Sheng-Hsiang, H., C. Ko-Shao, L. Hong-Ru, C. Shu-Ju and T. Tzu-Piao et al., 2009. Effect of plasma gas flow direction on hydrophilicity of polymer by small zone cold plasma treatment and hydrophobic plasma treatment. Int. J. Distributed Sens. Networks, 5: 429-436. DOI: $10.1080 / 15501320802473144$

Sun, X., G. Ding, H. Wang, Z. Jiang and B. Li et al., 2008. Design and simulation of a novel bridge-like coplanar waveguide for microelectromechanical systems. Microsyst. Technol., 14: 95-98. DOI: 10.1007/s00542-007-0395-0

Takeshi, T. and K. Hideomi, 2004. Development of a combinatorial atmospheric pressure cold plasma processor. Applied Surface Sci., 223: 259-263. DOI: 10.1016/S0169-4332(03)00928-0

Wei, Z.J., Y.Y. Wang and C.C. Wan, 2000. Study of wetter's in nickel electroforming of $3 \mathrm{D}$ microstructures. Mat. Chem. Phys., 63; 235-239. DOI: 10.1016/S0254-0584(99)00228-X

Wisitsoraat, A., V. Patanasetagul, A. Tuantranont and N. Poonnikorn, 2006. Design and Fabrication of Nonsilicon-based Piezoresistive MEMS Tactile Sensor. Proceedings of the 5th IEEE Sensors Conference, Oct. 22-25, Daegu, pp: 1317-1320. DOI: 10.1109/ICSENS.2007.355872

Wu, Y., C. Zhang and G. Ding, 2010b. Vertically bidirectional bistable microrelay with magnetostatic and thermal actuations. Proceedings of the IEEE International Conference on Micro Electro Mechanical Systems (MEMS), MEMS 2010-The 23rd IEEE International Conference on Micro Electro Mechanical Systems, Technical Digest, Jan. 24-28, Wanchai, Hong Kong, pp: 1139-1142. DOI: 0.1109/MEMSYS.2010.5442412

Wu, Y., G. Ding, C. Zhang, J. Wang and S. Mao et al., 2010a. Design and implementation of a bistable microcantilever actuator for magnetostatic latching relay. Microelectron. J., 41: 325-330. DOI: 10.1016/J.MEJO.2010.03.006

Xiao-Chuan, T., Z. Yu-Feng, Y. Zhen-Yu, W. Xi-Lian and L. Xiao-Wei, 2009. Micro direct methanol fuel cells based on silicon and non-silicon MEMS technologies. Opt. Precis. Eng., 17: 1218-1222. http://www.airitilibrary.com/searchdetail.aspx?Doc IDs $=1004924 x-201006-201004140033$ 201004140033-1218-1222
Yang, H. and S.-W. Kang, 2000. Improvement of thickness uniformity in nickel electroforming for LIGA process. Mach. Tools Manufact., 40: 10651072. DOI: 10.1016/S0890-6955(99)00107-8

Yang, S. and M.C. Gupta, 2004. Surface modification of polyethyleneterephthalate by an atmosphericpressure plasma source. Surface Coat. Tech., 187: 172-176.

DOI: 10.1016/J.SURFCOAT.2004.03.057

Youngsoo, K., Y. Chang-Ho, K. Kang-Jin and L. Yeonhee, 2007. Surface modification of porous nanocrystalline $\mathrm{Ti} \mathrm{O} 2$ films for dye-sensitized solar cell application by various gas plasmas. J. Vacuum Sci. Technol. Vacuum Surf. Films, 25: 1219-1225. DOI: $10.1116 / 1.2742392$

Yuan, L., F. Hongqiao and H. Shanglian, 2003. Study on a MEMS silicon-based non-silicon mirror for an optical switch. Chinese Opt. Lett., 1: 616-618. http://www.opticsinfobase.org/abstract.cfm?id=887 41

Yuan, L., Z. Yi and X. Xiaodong, 2006. Measurement of a silicon-based non-silicon MEMS micro mirror. Proceedings of the 3rd International Symposium on Precision Mechanical Measurements SPIE-The International Society for Optical Engineering, Oct. 13, SPIE. DOI: 10.1117/12.716174

Yusilawati, A.N., M. Maizirwan, M.S. Hamzah, K.H. $\mathrm{Ng}$ and C.S. Wong, 2010. Surface modification of polystyrene beads by ultraviolet/ozone treatment and its effect on gelatin coating. Am. J. Applied Sci., 7: 724-731. DOI: 10.3844/ajassp.2010.724.731

Zhu, L., Y. Feng, X. Ye and Z. Zhou, 2006. Tuning wettability and getting superhydrophobic surface by controlling surface roughness with well-designed microstructures. Sens. Actuat. A: Physical, 130: 595-600. DOI: 10.1016/J.SNA.2005.12.005

Zhuoqing, Y., D. Guifu, C. Haogang, X. Xiaoxue and W. Hong et al., 2009. Analysis and elimination of the 'skip contact' phenomenon in an inertial microswitch for prolonging its contact time. J. Micromech. Microeng., 19. DOI: 10.1088/09601317/19/4/045017 